\title{
Ethnicity and social exclusion in Colombia in 2012-2017
}

\author{
Edinson Ortiz Benavides and José Javier Núñez Velásquez
}

\begin{abstract}
This study aims to provide an approach to concepts and ways of measuring ethnicity and social exclusion that can be generalized to any context and time and, thus, make it possible to establish a statistically significant relation between these two categories. The methodology involves fuzzy sets and ordinary least squares regression, using data obtained from the Colombian National Quality of Life Survey for 2012-2017. At the $95 \%$ confidence level, it is concluded that when ethnicity increases by 1 percentage point, the degree of social exclusion in the country rises by 7 points. Other characteristics, such as having a darker skin tone, self-identifying with an ethnic group, being an immigrant and living in rural areas, produce similar effects.
\end{abstract}

\section{Keywords}

Ethnicity, indigenous peoples, people of African descent, ethnic and racial groups, economic, social and cultural rights, poverty, income, social isolation, measurement, social integration, social policy, Colombia

\section{JEL classification}

J10, J15, I32, F22

\section{Authors}

Edinson Ortiz Benavides is Associate Professor in the Economics Department of the University of Nariño (Colombia) and holds a PhD from the University of Alcalá (Spain). Emails: edinson.ortiz@uah.es, edinson@udenar.edu.co.

José Javier Núñez Velásquez is Associate Professor in the Economics Department of the University of Alcalá (Spain). Email: josej.nunez@uah.es. 


\section{Introduction}

Ethnicity and social exclusion are two categories on which there is a lack of consensus in terms of conceptualization, measurement and interrelationships. Although recently coined expressions, their roots can be traced centuries back in sociology, biology or anthropology. This study does not seek to provide a compendium on the subject, but to offer an approach to concepts and ways of measuring these phenomena that can be generalized to any context and time period, and to establish a statistically significant relation between the two.

The concepts of race, ethnic origin and immigration, alongside those of gender, class, age and religion, underpin a range of cultural, economic and social systems and mechanisms of domination that prevent large human groups gaining equitable access to the enjoyment of symbolic and consumer goods (Bello and Rangel, 2000, p. 4). The analyses and research projects undertaken in the last two decades, on social exclusion, poverty and inequality in Latin America, have highlighted the situation of disadvantage and marginalization suffered by indigenous populations and Afrodescendent groups - which has its roots in colonialism and the slavery system of which they were victims (Valdivia, 2011, p. 20). This has led to a recognition of the existence of certain "ethnic gaps" which highlight the difference in the degree and manner in which ethnic-racial groups confront the problems of poverty and social exclusion (Valdivia, 2011, p. 20).

Using statistical data from Colombia's National Quality of Life Survey for 2012-2017, the study aims to align the concepts mor closely to the categories available in the data and to identify the evolution of these phenomena and the relations between them in that period. To that end, this article has been divided into five sections including this introduction: section II addresses ethnicity, its conceptual development and the establishment of an indicator (the ethnicity factor (factor de etinicidad - fet); section III deals with the dimensions and complexity of social exclusion, and proposes an alternative way of measuring it based on the degree of social exclusion (grado de exclusión social - ges); section IV reports the results obtained from the established indicators, along with their evolution and the relations between them; and section $\mathrm{V}$ presents the main conclusions of the study.

\section{Ethnicity: social and economic category}

\section{The concept of ethnicity}

Although the concept of ethnicity emerged half a century ago, it does not command consensus. Negligible progress has been made in defining it clearly; and, in fact, it is openly confused with the notions of race and ethnic origin, which the concept was intended to overcome. Ever since the American sociologist David Riesman first referred to the concept in 1953, ethnicity has been associated with the culture of belonging, inequality, discrimination and the domination of one social group over another, on the grounds of putative superiority, or on the basis of better and more legitimate rights than those of the people who are devalued and excluded (Oommen, 1994). Like other categories, such as gender and class, ethnicity underpins a wide range of institutional, cultural, economic and social systems and mechanisms of domination. Through these, large human groups suffer clear and repeated processes of social exclusion and are denied equal access to the enjoyment of symbolic and consumer goods (Bello and Rangel, 2000).

Ethnicity is thus a socially constructed category with strong economic implications. It also encompasses other categories that differentiate between population groups in a given context and time. These categories are race, ethnic origin and immigration, which are essential components of ethnicity, and together represent the key elements of discrimination and social exclusion in a country. 


\section{The components of ethnicity}

\section{(a) Race}

Race is the first category or component of ethnicity and is constructed to justify phenotypic differentiation between human beings. The concept of race includes the taxonomic division of the human genus based on biological, morphological and physiological differentiations. However, according to Stavenhagen (2002), the term race has been used not as an empirically demonstrated taxonomic category in biology, but as a social construct that uses certain visible biological traits as classification criteria. This has occurred even though genetic biology has shown that no such racial division exists in the human species, and that all human beings share the same biological traits (Antón and Del Popolo, 2009).

Wade (2011) posits three theories of the meaning of race. The first has to do with human genetic variation. The biological constitution of human beings clearly varies in some very obvious ways. The question is whether such variation can be classified in a discrete number of defined categories, called "races", each of which has certain characteristics in common, such as skin colour, hair type, blood type, or aspects of genetic constitution. If so, the concept of race would be useful for talking about variations in human nature. In fact, that is precisely the meaning of race that predominated in Western popular and scientific circles throughout the nineteenth and for much of the twentieth centuries (Wade, 2011, p. 208).

The second, more controversial, theory holds that superficial variation in external appearance correlates with other human characteristics. An individual's skin colour is greatly influenced by inherited genes; the question is whether those same genes, or some correlated part of the genetic complement, also exert a significant influence on cognitive abilities, such as "intelligence", or perhaps on skills such as strength or speed. This second theory fit the first like a glove and also predominated in the nineteenth and much of the twentieth centuries. A "race" could thus be defined not only in terms of biological markers such as skin colour and facial features, but also in terms of moral and intellectual characteristics (Wade, 2011, p. 209).

The third theory of race holds that, whatever human genetic variation exists, it cannot be usefully described in terms of race; and that race is an idea, with no biological relevance to human potential. Its status as an idea, however, does not diminish its enormous social importance. Even if race has no biological basis in human nature, people are clearly primed to discriminate against others whom they define as racially different. [...] This third theory is based on the currently accepted idea that "races" are social constructs, while recognizing that the concept of race remains a very important and often deeply rooted notion that affects people's behaviour and their opportunities in substantial ways (Wade, 2011, pp. 209-210).

Rangel (2004) also refers to this third theory and states that, from the early years of the twentieth century, theories that disdained morphological classifications of human beings became increasingly accepted, and the concept of race lost its scientific importance and was partially abandoned. Biology started to recognize the non-existence of subdivisions of the human species that could be justified on the basis of genetic factors, and which would correlate with certain distinct physical, psychological, moral or intellectual qualities. It was then realized that the differences between human groups could only be explained scientifically on the basis of their historical and cultural origin; and the concept of ethnicity gained analytical importance, replacing that of race (Rangel, 2004, pp. 31 and 32).

\section{(b) Ethnic origin}

The concept of ethnic origin as a second component of ethnicity is derived from the Greek word ethnos, which in turn comes from the term ethnicus. The word ethnos originally meant people or nation 
and was used interchangeably with the discredited category of race, to characterize ethnic groups or the ethnic identities that comprised them. According to Valdivia (2011), the ethnic conceptualization has recently developed mainly through two major theoretical strands. The first is known as the primordial approach, according to which ethnic groups are defined by characteristics that are inherent to their culture, such as language, music, customs, ancestors, clothing, institutions and values, among others. The second theoretical strand embraces several positions that emerged in opposition to what has been called "primordialism". These form part of a contextual or circumstantial approach and share two basic ideas: firstly, there are no predefined and immutable ethnic identities, since identity is dynamic and subject to changes in the historical development of the groups in question; and, secondly, identities depend largely on the social, political and cultural environment in which peoples or population groups develop; so they reflect certain strategic positionings defined from the context (Valdivia, 2011, p. 30).

In general, the conventional definitions of ethnic identity tend to include elements of both perspectives -the "primordialist" and the "circumstantial" or "constructivist". Thus, the concept of "ethnic group" usually refers to a community that shares a past (tradition), a culture and a form of social organization. An ethnic group also perceives itself, and is perceived by others, as a collective with common social attributes and cultural elements (language, religion, nationality or "race"). Its existence implies shared values and beliefs, and involves a common sense of identity (Valdivia, 2011, p. 32).

Ethnic origin, therefore, implies an ethnic group understood as a community that not only shares a racial identity, but also recognizes itself as such and shares customs, territory, beliefs, worldview and linguistic or dialectal and symbolic notions. Nonetheless, an ethnic group thus understood does not imply the existence of class-based, political and economic homogeneity within the group or community. The term only makes it possible to redefine collective identity. In other words, an ethnic group has social, economic and political differentiations of its own, while maintaining a strength as a cultural group, both inwardly and outwardly (Hopenhayn and Bello, 2000).

\section{(c) Immigration}

In the context of this research, immigration - meaning the phenomenon whereby people move their habitual residence from one country to another - constitutes the third component of ethnicity. This is because, by crossing political borders, migrant populations assume the characteristics of ethnic groups and are perceived as such, both by themselves and by the host society. These population groups may originate from a particular region, country or group of countries, as exemplified by the Hispanic community in the United States.

Immigration, thus defined, is a phenomenon that has been present throughout the history of humanity; has conditioned the configuration of peoples and later of states; and has given rise to wide disparities between the most and least developed countries in the world in terms of socioeconomic circumstances, opportunities and human security. However, the migrations that have taken place since the start of the twenty-first century are unprecedented. They have recently attained their largest ever volume and display characteristics that distinguish them from those of earlier periods. This has led to a new conceptualization of the phenomenon, framed in what some analysts refer to as "the new era" of international migrations (Arango, 2003, cited in Godínez-Montoya, Figueroa-Hernández and Pérez-Soto, 2014, p. 13).

This new era is set in a scenario of economic, cultural and informational globalization, which stimulates broad segments of the population to respond ever more rapidly to information and opportunities that originate beyond national borders (CONAPO, 2009, cited in Godínez-Montoya, Figueroa-Hernández and Pérez-Soto, 2014, p. 13). These factors, in conjunction with unequal distributions of economic activity, income and poverty, as well as economic or political crises, or war, facilitate migratory movements. This 
occurs because people are constantly stiving for economic well-being, security and a better present and future social position; and, sometimes with great sadness, they come to realize that they will find it difficult to achieve these goals in their countries of origin (Peligero Escudero, 2006).

In the case of Latin America in particular, political and economic crises generate uncertainty about the future of countries and people. Although ECLAC data (2008) show that trends in economic growth, poverty reduction and job creation have been positive in recent years, the feeling of uncertainty generated in the region does not dissipate with a few economically bountiful years. The structural problems of the Latin American economy persist, including the dependency and vulnerability of domestic economies, disparities between different regions within countries, inequality between different social classes, unequal income distribution and a lack of efficient public services (Tedesco, 2010, p. 123).

\section{Measuring ethnicity in practice}

At the global level, but particularly in Latin America, there is growing consensus on the need to raise the profile of the different ethnic groups living within a country's borders, in order to identify their problems and needs, give them due recognition and accord them a leading role in decisions related to their own development. In this regard, initiatives have been implemented to include ethnic/racial identification in the official statistics generated in several countries, to have information available for designing and developing social inclusion policies that take into account the social, economic, political and cultural problems of these historically excluded groups (Schkolnik and Del Popolo 2006, p. 249, cited in Valdivia, 2011, pp. 19 and 20).

In Latin America, progress has clearly been made since 1990 and especially since the turn of the century. Recent years have seen initiatives to create systems of indicators to track the social and economic situation of ethnic groups, a concept that constitutes the second component of ethnicity and is often confused with race and immigration. An example of this is the use of black, mulatto, Afro-Hispanic, white-Hispanic, Chinese and other categories in some of the region's censuses.

Although there is interest in making the general characteristics of the countries' ethnic groups visible, there are several challenges that hinder the international comparability of the data, which are related to conceptual and methodological definitions. Estimates of the indigenous and Afrodescendent population, for example, have historically been controversial, both because of the scarcity of reliable data and owing to the diversity of criteria on which the estimations have been based. In many cases, the information obtained from censuses, especially in the 1980s and 1990s, also differs by very high percentages from other estimates obtained by ethnic authorities and scholars on the subject in the same periods or between censuses (Schkolnik, 2009).

In the vast majority of Latin American countries, ethnic self-identification categories tend to be conflated with those of race or immigration in censuses, not only among the reply alternatives, but also sometimes in the wording of the question itself (Schkolnik, 2009). The potential consequences of this on the quantification of ethnic groups depend on the sociocultural and geographic context of each country. Accordingly, there are multiple biases deriving from the operational decisions adopted in the census, which may or may not have involved participation by the indigenous, Afrodescendent or other groups, themselves, during the discussion process prior to implementation of the census (Schkolnik, 2009, p. 85).

Given the importance of including ethnic statistics as a way to formulate public policies aimed at improving the living conditions and social inclusion of these populations in the countries of the world generally, and of Latin America and Colombia in particular, data collection tools need to be refined to completely separate the ethnic origin category from those of race and immigration, and to consider the three categories as essential components of a broader concept of ethnicity. 


\section{The ethnicity factor: a methodological proposal}

Aside from the consensuses achieved, there has been growing recognition of the complexity and importance of the ethnic issue in the last three decades. Some analysts have questioned the possibility of "measuring" ethnicity through discrete and even dichotomous categories (Valdivia, 2011, p. 52). Others claim that the eminently political and contextual nature of the definitions and ethnic categories used in the censuses of each country make it unfeasible, or at least relatively so, to establish a single approach for application worldwide (Morning, 2008, p. 28, cited in Valdivia, 2011). This is because the wordings of questionnaires and census questions on ethnic origin/race depend on the political interpretations, agendas and motivations that lead the governments of each country to undertake this task (Valdivia, 2011, p. 45).

Overcoming this problem requires redefining the census or household survey questionnaires, in order to disentangle the constituent elements of ethnicity and then combine them in a comprehensive measure, which this study refers to as the "ethnicity factor" (fet).

To construct the ethnicity factor, a variable needs to be defined for each of its categories or components. The variables in question must be adaptable to any country, categorical and assessed on a single scale to make them comparable. This task of definition is carried out below.

\section{(a) Definition of the variable corresponding to race}

Currently, in the vast majority of countries, ethnic origin and race are linked in the same questions in the surveys. This occurs, for example, with the categories black, white, mixed race (mestizo) and indigenous, among others, which refer indistinctly to the colour of a person's skin and her identification with a particular ethnic group.

In calculating the ethnicity factor, it is proposed to use skin colour (color de piel - $c p$ ) as a variable based on the tonality $(R)$ imputed by the interviewer. Although it has been scientifically proven that neither the concept nor the conception of race can be used to classify the human species, skin colour is known to have instrumental utility in discerning how opportunities are distributed in societies. Moreover, in the case of several indicators of well-being, the interviewer's external classification or imputation based on a colour palette (from lightest to darkest) has proven a better predictor of ethnic-racial inequalities than self-classification, whether ethnic or racial (Telles, 2014).

For example, the Project on Ethnicity and Race in Latin America (PERLA), which was implemented in 2010 by Professor Edward Telles of Princeton University, made an effort to gather and analyse survey data, with a view to exploring a wide range of ethno-racial issues in the region. As part of the project, a survey conducted in four countries (Brazil, Colombia, Mexico and Peru) provided much needed data to identify conditions in the region. From the survey, Telles and Steele (2012) show that, in nearly all of the region's countries, skin tone is related to educational opportunities, measured by the number of years of schooling. In other words, as the authors claim, Latin American societies are "pigmentocracies", in which skin colour (along with social class, gender and other factors) affects life opportunities.

The chromatic scale used in the PERLA survey had 11 skin tones ranging from lightest to darkest. This scale is used again in the fet, with $R$ being given the value 0 for the lightest skin colour and 10 for the darkest. It is thus proposed to follow the style of the PERLA survey by using a question that could be common to all countries, in which the interviewer assigns a number between 0 and 10 to the respondent's skin colour. A colourimeter could also be used, since the measurement of skin pigmentation has been shown to be scientifically possible. The colourimeter returns a skin colour rating ranging from 0 to 100, where 0 is the darkest colour and 100 is the lightest. 
Thus, in order to normalize the variables to values of between 0 and 1 , the following equation is used to obtain the component corresponding to skin colour $(c p)$

$$
c p=R / 10
$$

\section{(b) Definition of the variable representing ethnic origin}

In recent decades, census questionnaires have tended to use self-identification questions to identify ethnic groups. Nonetheless, the wording of the questions varies widely, as do the categories that are available in the replies and the adaptation of concepts and methodologies to each national reality. This affects the results. It can be argued that the complexities of using ethno-racial categories, compounded by the different ways of measuring and approaching this dimension, largely explain why the results of the magnitudes and proportions that appear in each ethno-racial classification diverge significantly in the same contexts and times (Schkolnik, 2009).

In practice, ethnic self-identification is complemented by mother tongue and language, culture and customs, physical traits and belonging to a people, among others. Given the international consensus in this regard, it is proposed to use self-identification with an ethnic group (autoadscripción a un grupo étnico - age) as a variable in the calculation of the ethnicity factor. The justification for this that it is the only criterion that respects the subjective dimension of the respondents and is, therefore, the least ethnocentric criterion. Moreover, this criterion is characterized by being the most encompassing, at least theoretically, since it includes all persons who declare themselves as members of an ethnic group, irrespective of what each person means by the term (Goldberg, 2007, p.7). Based on this self-recognition of identity as one of the basic dimensions for the treatment of ethnic groups, the other questions of common origin, culture and territoriality can be explored in greater depth.

A question that would make it possible to establish this variable in the case of Colombia would be the following:

According to your culture, people or physical features, are you, or do you consider yourself, a member of any of the following ethnic groups?

(a) Indigenous

(b) Roma (or gypsy)

(c) Afrodescendent

(d) None of the above

If the reply is (a), the respondent should also be asked to which village he/she belongs, and whether he/she speaks the native language. If the reply is (b), the respondent should be asked if he/ she speaks the Romani language. If the reply is (c), the respondent should be asked to which people he/she belongs (Raizal of the San Andrés Archipelago, Palenquero or Afro-Colombian), and whether he/she speaks the mother tongue.

These questions could be extended to other Latin American countries, and could also be adapted without much effort to North American, European, Asian and African countries, because ethnic groups are recognized in all of them.

The variable age takes dichotomous values: 1 , if the person self-identifies with any ethnic group $(a, b, c)$; or 0 , if the person does not self-identify with any group (d). 


\section{(c) Definition of the variable representing immigration}

As mentioned above, when people cross their national borders in large collectives, the members of these collectives recognize themselves as such and show themselves to the outside world in accordance with the cultural traits and other material and immaterial (symbolic) elements they share. This engenders a feeling of group identity, or belonging, which is fundamental for the social reproduction of the collective in question (Fernández de Labastida, undated, p. 2).

In particular, ethnicity constitutes the social process that reactivates collective identities and feelings of identification with a set of common cultural traits. Individuals who have the same ethnic identity may or may not share physical traits; but what really defines the ethnic group is the sense of belonging that all of its members feel, as well as difference or contrast with respect to other groups. This type of collective feeling proliferates in certain contexts in which various cultures and communities coexist. In this sense, economic globalization is reactivating ethnicity, since one of its most direct consequences is an intensification of migration worldwide (Fernández de Labastida, undated, p. 2).

As a result of immigration, people from different cultures coexist in the same space and form distinct social groups. The relationship between these groups is usually asymmetric: the host society or receiving community is the dominant group, whereas the immigrant collective is subordinate. This generates relationships between minorities and majorities that indicate the social position or structural importance of each group. A minority group is one that, regardless of the number of people in it, lives in a situation of inferiority and subordination relative to the majority group, which holds the power. In any event, immigration generates and reactivates ethnicity because it implies the introduction of an other (the immigrant) into a territory and a culture that identifies with the "us" (Blanco, 2000, p. 108).

To calculate the ethnicity factor, the immigration variable $(\mathrm{im})$ is incorporated by defining the nationality of the respondent and his/her parents. This entails finding out whether the respondent head of household was not born in the country in which the questionnaire is being applied (jfb), whether the respondent's mother was not born in that country $(\mathrm{mb})$ and whether the respondent's father was not born in that country either (pb). Each of these dichotomous variables takes the value 1 in the affirmative case and 0 otherwise. With these values, the immigration variable $(i m)$ is calculated as follows:

$$
i m=0.5 * j f b+0.25 * m b+0.25 * p b
$$

\section{(d) Calculation of the ethnicity factor}

Once the three variables that comprise the ethnicity factor have been defined, the values that they can take are shown in table 1.

Table 1

Variables that comprise the ethnicity factor and values they can take

\begin{tabular}{|c|c|}
\hline Variable & Values \\
\hline Skin colour $(c p)$ & $\begin{array}{l}\text { [0]: very light skin tone } \\
{[0-1] \text { : intermediate skin tones }} \\
{[1] \text { : very dark skin tone }}\end{array}$ \\
\hline $\begin{array}{l}\text { Self-identification with an } \\
\text { ethnic group (age) }\end{array}$ & $\begin{array}{l}\text { [0]: the head of household does not self-identify with any ethnic group in the country } \\
\text { [1]: the head of household self-identifies with an ethnic group in the country }\end{array}$ \\
\hline Immigration (im) & $\begin{array}{l}\text { [0]: the head of the household and both parents were born in the country where the survey is applied } \\
{[0.25] \text { : the head of household was born in the country where the survey is applied, and only one of }} \\
\text { his/her parents is a foreigner } \\
0.5] \text { : both parents or the head of household are foreigners }[0.75] \text { : the head of household and only } \\
\text { one of his/her parents are foreigners }[0.75] \text { : the head of household and only one of his/her parents } \\
\text { are foreigners } \\
\text { [1]: the head of the household and both parents are foreigners }\end{array}$ \\
\hline
\end{tabular}

Source: Prepared by the authors. 
The equation used to calculate the ethnicity factor is as follows:

$$
f e t_{i}=\frac{\sqrt{c p_{i}^{2}+a g e_{i}^{2}+i m_{i}^{2}}}{\sqrt{c p^{2}+a g e^{2}+i m^{2}}} \rightarrow f e t_{i}=\frac{\sqrt{c p_{i}^{2}+a g e_{i}^{2}+i m_{i}^{2}}}{\sqrt{3}}
$$

where:

fet $t_{i}=$ ethnicity factor of household $i ; c p_{i}=$ skin colour of the head of household $i$; age $_{i}=$ self-identification with an ethnic group by the head of household $i ; i m_{i}=$ immigration status of the head of household $i$, and 1 is the maximum value that each of the ethnicity variables ( $c p$, age and $i m$ ) can take.

The values of the ethnicity factor range from 0 to 1 . The higher the value of $f e t$, the greater the ethnicity of the household. This indicator makes it possible to establish and compare ethnicity values in different contexts - for example, identifying which household, city or country is more ethnic than another and, therefore, whether it is more exposed to certain phenomena, such as social exclusion or poverty.

\section{Social exclusion}

\section{The concept of social exclusion}

Social exclusion is a very dynamic concept that appears as a phenomenon exclusive to post-industrial or advanced societies that result from greater global, technological and economic development. Following the crisis and subsequent restructuring of the welfare state, the social contract in these countries has changed. As a result, the welfare system of the new sociopolitical era does not ensure the integration of all social classes (Raya Díez, 2006, p. 30, quoted in Hernández Pedreño, 2008).

Although this concept is new to economic science, it is not new to sociology and has the advantages and challenges that any process approach entails. Its richness lies in its multidimensional nature; but, at the same time, it leaves much room for divergences between analysts to emerge, as noted by Trouillot (2000, p. 111). In this sense, social exclusion is a concept and a phenomenon that is still under construction and reconstruction by the social sciences - proof of which is the dispersion of meanings and discourses that denote different realities for the same process (Hernández Pedreño, 2008, p. 29).

Specifically, social exclusion can be defined as a set of structural [and institutional] mechanisms that [systematically] prevent certain social groups from participating fully in the economic, social, political and cultural spheres of society (Valdivia, Benavides and Torero, 2007, p. 604). These mechanisms cause lack of access to health services, residential marginalization, inadequate engagement with the labour market, tendencies towards occupational segregation, constraints on receiving good quality education and lack of effective political representation in the State, among other problems (Figueroa, Altamirano and Sulmont, 1996; Ñopo, Saavedra and Torero, 2004; Torero and others, 2004, cited in Valdivia, Benavides and Torero, 2007). The World Bank (2013) states that individuals and groups are excluded or included based on their identity. Among the most common group identities resulting in exclusion are gender, race, caste, ethnicity, religion and disability status. "Social exclusion based on such group attributes can lead to lower social standing, often accompanied by lower outcomes in terms of income, human capital endowments, access to employment and services, and voice in both national and local decision making" (World Bank, 2013, p. 5).

"Exclusion plays out through both tangible and intangible practices and processes. Although it is most evident in differences in "tangible" outcomes, it is rooted in intangible social norms and beliefs, which in turn lead to stereotypes, prejudices and stigmas. These intangible features are socially constructed and played out by both the excluder and the excluded" (World Bank, 2013, p. 8). 
Based on the characteristics described above, social exclusion can be analysed and understood as a multidimensional process that often tends to accumulate, combine and separate, both individuals and groups, from a series of social rights such as work, education, health, culture, economy and politics, to which other groups do have access and the possibility of enjoying, and which, sooner or later, end up nullifying the concept of citizenship (Jiménez Ramírez, 2008, p. 178).

Without delving into an entire historical compendium, it could be said that "initially, the concept of social exclusion was used in Europe - first in France, Italy and the Nordic countries - to refer to the new social and economic problems associated with globalization, such as: precarious employment and underemployment; the social, economic, political and cultural insertion of immigrants; and social disintegration generated by ethnic differences" (Gacitúa and Davis, 2001, p. 13). It originates largely in theoretical contributions developed in earlier times by classic figures of sociology such as Marx, Engels, Durkheim, Tönnies, Bourdieu and Parkin, with special emphasis on the dual alienation of the "social class" and the "insider-outsider" dynamic. However, the most recent [contributions] to the concept of social exclusion are generally attributed to René Lenoir (1974), in his pioneering work Les exclus: un Française sur dix (Jiménez Ramírez, 2008), which estimated that 1 in 10 French people could be considered excluded, and even identified the social groups in question.

The influence of the European Union in generalizing the concept of social exclusion has been highlighted by many social researchers. The term first appeared in 1989 in the Second European Poverty Programme; and the European Union was the driving force behind the debate on poverty and new forms of inequality, marginalization and social vulnerability. In the late 1980s and early 1990s, the European Commission tasked itself with establishing a social dimension to European Union policy, by promoting debate, action and research on poverty (IGOP, 2003, p. 21).

In the First European Poverty Programme (1975-1980), citizens were considered poor if their resources were so meagre that they were excluded from the levels of coexistence considered acceptable in their countries of residence; that is, poverty was measured in strictly monetary terms (distribution of income or expenditure). It is in the Second European Poverty Programme (1985-1989) where explicit reference is made to social exclusion; and although the programme also emphasizes lack of resources, it extends its content to those of a social and cultural nature, that is, to all mechanisms through which families or groups of people may feel excluded (Estivill, 2004, pp. 29-38, quoted in Hernández Pedreño, 2008). However, the term social exclusion was only established in 1991 in the European Community programme concerning the economic and social integration of the economically and socially less privileged groups in society "Poverty 3", and in the guidelines of the Observatory of National Policies to Combat Social Exclusion (IGOP, 2003, p. 22).

This shows that social exclusion is a phenomenon of modern societies that goes beyond the concepts of poverty, marginalization and inequality: according to this conception, a group of people living in poverty is always considered excluded, but not every socially excluded group is poor.

\section{Alternative measurement}

The concept of social exclusion can be an effective research tool for comparing the different types of social policy efficacy as the main mechanism for preventing the emergence and spread of social exclusion. The concept's implementation in the political and scientific discourses provides an opportunity for international comparisons aimed at finding common and different manifestations of exclusion in countries with alternative approaches to social policy formation. However, a prerequisite for cross-cultural comparisons is the use of equivalent tools for data collection. Making such a comparison implies the structural similarity of the phenomenon that is studied in different societies (Loktieva, 2016, pp. 148-149). 
There is a general consensus in the literature that social exclusion has the following characteristics: it is multidimensional; it is dynamic; it occurs in a given time and place; it is relative (or comparative); it is structural; it is relational; and it has to do with social processes. On the basis of these characteristics, and given the importance that the phenomenon has in the approach to public policy, over the past two decades, researchers have begun to quantitatively operationalize social exclusion. Early efforts relied heavily on familiar and well-used constructs, such as personal or household income and consumption below a poverty line (Good Gingrich and Lightman, 2015). Most recent studies operationalizing social exclusion in quantifiable terms use a combination of material and social indicators, thus emphasizing its multidimensional nature. These authors propose an index of social exclusion for Canada that includes multidimensional characteristics of material deprivation and social isolation; and they confirm that social exclusion falls most heavily on the migrant population and on ethnic minorities and darker-skinned groups.

In research on Ukraine and several European countries, Loktieva (2016) follows this multidimensional approach and concludes that the structures of distributional and relational components of social exclusion are similar in countries with different levels of socioeconomic development and welfare models.

Many of the elements that Alkire and Foster (2007) use in the calculation of multidimensional poverty also apply to social exclusion, since it has the aforementioned characteristics and is also defined by the accumulation of deficits (deprivations) that are interrelated and feed back on each other. In this sense, Domínguez and Núñez (2013) have also developed a synthetic index of social exclusion using a set of quantitative and qualitative indicators obtained from the Spanish Living Conditions Survey. In the index, the authors use the social exclusion indicator they proposed in 2009, based on fuzzy sets.

This study uses the degree of social exclusion variable (ges) as an alternative measure, and as a variation on the multidimensional poverty index (MPI) used by the National Administrative Department of Statistics (DANE) of Colombia. This is based on household deprivations in 15 variables and 5 dimensions, relative to a normative threshold (zj) established for each variable.

The deprivation is established as follows:

$$
\begin{aligned}
& X=\left[\begin{array}{ccc}
x_{11} & \cdots & x_{1 j} \\
\vdots & \ddots & \vdots \\
x_{N 1} & \cdots & x_{N j}
\end{array}\right] ; \quad \bar{X}=\left[\begin{array}{ccc}
\bar{x}_{11} & \cdots & \bar{x}_{1 j} \\
\vdots & \ddots & \vdots \\
\bar{x}_{N 1} & \cdots & \bar{x}_{N j}
\end{array}\right] ; \quad \bar{x}_{i j}\left\{\begin{array}{l}
1 \text { if } x_{i j}<z_{j} \\
0 \text { yes No }
\end{array}\right. \\
& Z=\left[\begin{array}{llll}
z_{1} & z_{2} & \cdots & z_{j}
\end{array}\right] ; \quad W=\left[\begin{array}{llll}
w_{1} & w_{2} & \cdots & w_{j}
\end{array}\right]
\end{aligned}
$$

$C=\left(c_{1}, c_{2}, \ldots c_{N}\right)$, where $c_{i}(i=1,2,3, \ldots N)$, but $C=\bar{X} . W$ Weighted vector of deprivations in which:

$x_{i j}=$ Characteristics of household $i$ in dimension $j$

$\bar{x}_{i j}=$ Deprivation of household $i$ in dimension $j$

$z_{j}=$ Threshold in dimension $j$

$w_{j}=$ Weight assigned to dimension $j$

$c_{i}=$ Weighted deprivation of household $i$

$N=$ Total sample households

$J \quad=$ Total dimensions or variables

The weight $w_{j}\left(\sum_{j=1}^{J} w_{j}=1\right)$ can be constructed at the discretion of the national statistical authorities, as is generally the case. In some countries equal weights are assigned to the dimensions and to the variables of each dimension; but, because the number of variables in each dimension varies, the weighting of each group of variables is different. Other ways of calculating the weights include the following: 
Assign equal weighting to the variables:

$$
w_{j}=\frac{1}{J}
$$

Assign weighting according to the relative weight of the variables:

$$
w_{j}=\frac{f_{j}}{F} \text {, where } f_{j}=\frac{1}{N} \sum_{i=1}^{N} \bar{x}_{i j} \text { and } F=\sum_{j=1}^{J} f_{j}
$$

In this research, the weights $\left(w_{j}\right)$ will be estimated by considering the inverse functional relation that exists between the system of weights and the frequencies corresponding to household nondeprivations $\left(g_{j}=1-f_{j}\right)$ proposed by Dagum, Gambassi and Lemmi (1992) and adjusted by Domínguez and Núñez (2013). In this case:

$$
w_{j}=\frac{v_{j}}{V} ; v_{j}=\ln \left(1 / g_{j}\right) \text {, where } g_{j}=\frac{1}{N} \sum_{i=1}^{N}\left(1-\bar{x}_{i j}\right) \text { and } V=\sum_{j=1}^{J} v_{j}
$$

which gives the following equality:

$$
\text { ges }_{i}=c_{i}
$$

\section{Results}

\section{The database}

To apply the methodologies described above, data on 121,802 households were drawn from the National Quality of Life Survey (ECV) of Colombia spanning 2012-2017. The households were statistically representative, both nationally and in the urban and rural domains. The ECV is implemented by DANE for the purpose of collecting data on different aspects and dimensions of household welfare, such as access to public, private or communal goods and services, health, education and childcare for the under-fives, among others. Considering these issues then makes it possible to analyse the factors that explain the different standards of living in society. ${ }^{1}$

\section{The ethnicity factor (fet) in Colombia}

Applying the proposed methodology to the available data makes it possible to obtain the ethnicity factor for Colombia by combining the variables corresponding to skin colour, self-identification with an ethnic group and immigration. The results are shown in Figure 1.

\footnotetext{
1 The information is obtained in the form of microdata from the DANE website (see [online] www.dane.gov.co).
} 
Figure 1

Colombia: ethnicity factor, 2012-2017

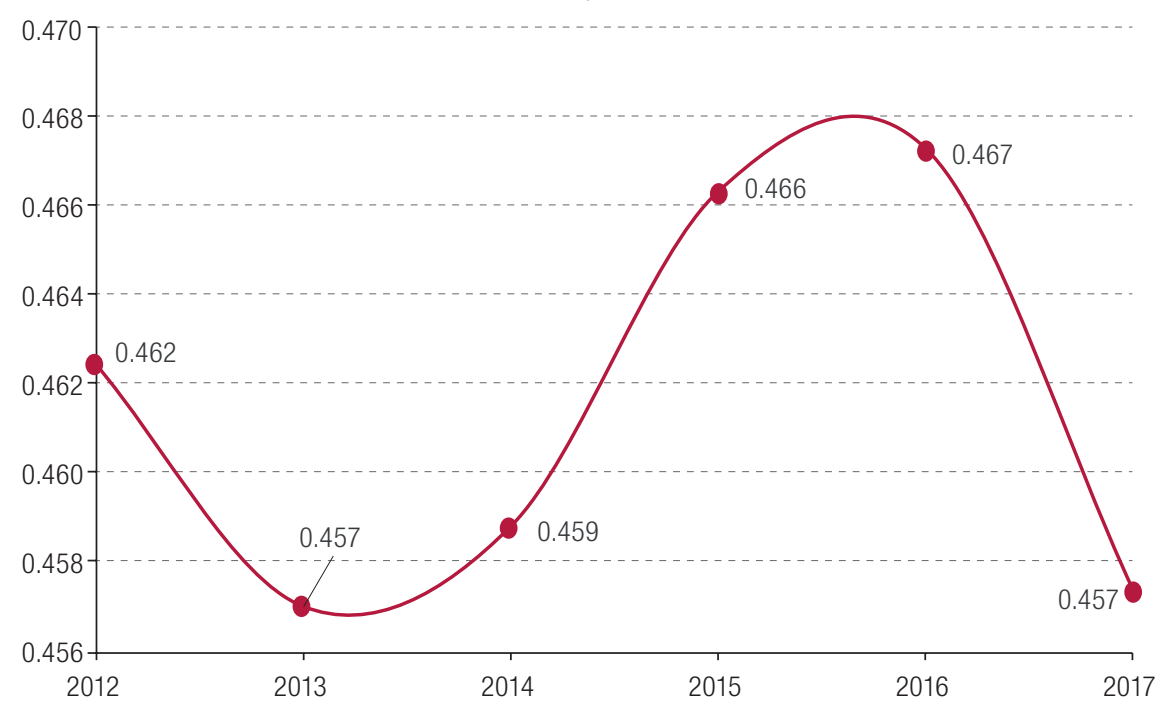

Source: Prepared by the authors.

The data show that Colombia is a highly ethnic country: in the period analysed its ethnicity factor is approximately 0.46 on a scale of 0 to 1 . The values form a sine wave that exhibits a significant upturn in 2015 and 2016, owing partly to the slight economic improvement that occurred in the country in those years.

With respect to each of the variables that comprise the ethnicity factor, figure 2 shows that skin colour and self-identification with an ethnic group also exhibit a highly dissimulated sinusoidal behaviour pattern that corresponds to that of the factor as a whole. Moreover, a generalized rise can be discerned in immigration, with a pronounced spike in 2017 due mainly to the large-scale arrival of migrants from the Bolivarian Republic of Venezuela.

Figure 2

Colombia: components of ethnicity, 2012-2017

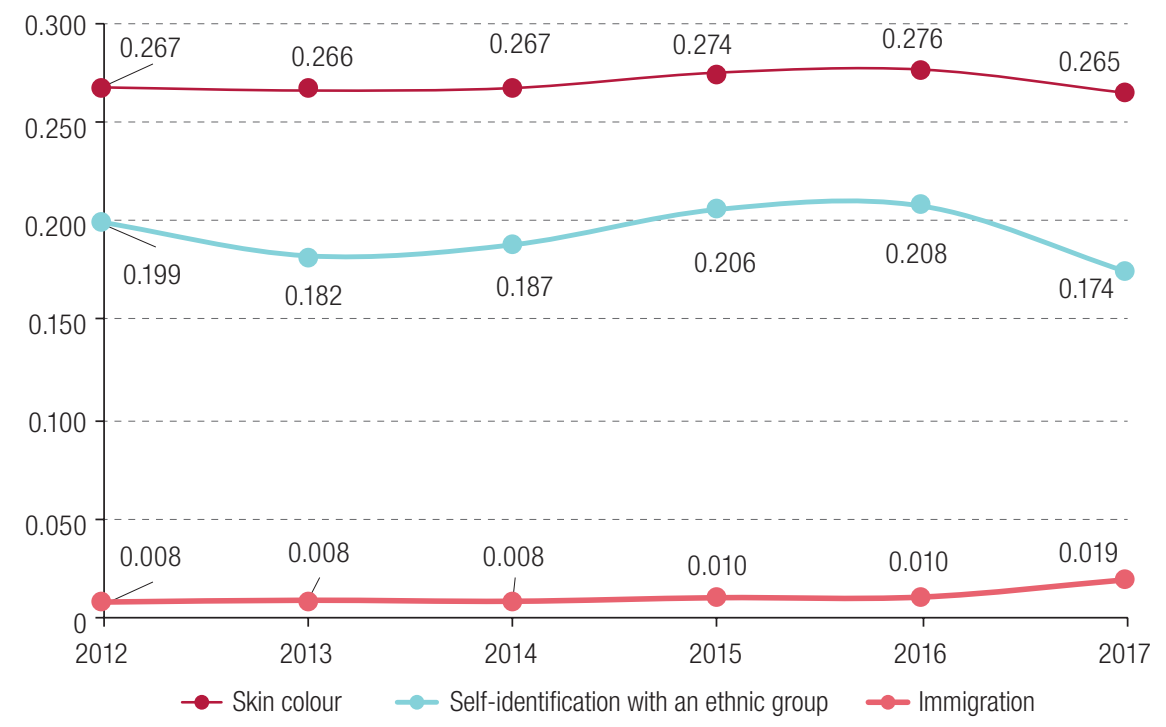

Source: Prepared by the authors. 
Table 2 displays the components of ethnicity in Colombia in greater detail.

Table 2

Colombia: ethnicity factor, by group of interest, 2012-2017

\begin{tabular}{lllllllll}
\hline Variable & Criteria & 2012 & 2013 & 2014 & 2015 & 2016 & 2017 & Total \\
\hline \multirow{2}{*}{ Skin colour (cp) } & $<=0.45$ & 0.418 & 0.407 & 0.407 & 0.409 & 0.409 & 0.406 & 0.410 \\
\cline { 2 - 8 } & $>0.45$ & 0.773 & 0.772 & 0.772 & 0.772 & 0.772 & 0.773 & 0.772 \\
\hline \multirow{2}{*}{$\begin{array}{l}\text { Self-identification with an } \\
\text { thnic group (age) }\end{array}$} & No & 0.389 & 0.389 & 0.389 & 0.389 & 0.389 & 0.392 & 0.389 \\
\cline { 2 - 8 } & Yes & 0.760 & 0.764 & 0.763 & 0.764 & 0.765 & 0.767 & 0.764 \\
\cline { 2 - 8 } & Roma & 0.577 & 0.612 & 0.577 & 0.625 & 0.577 & 0.577 & 0.589 \\
\cline { 2 - 8 } & Afrodescendants & 0.773 & 0.772 & 0.772 & 0.772 & 0.772 & 0.773 & 0.772 \\
\cline { 2 - 8 } & Indigenous & 0.739 & 0.739 & 0.738 & 0.739 & 0.739 & 0.740 & 0.739 \\
\hline \multirow{2}{*}{ Immigration (im) } & No & 0.460 & 0.455 & 0.457 & 0.464 & 0.464 & 0.452 & 0.459 \\
\hline \multirow{nyyyyyyy}{*}{ Gender } & Yes & 0.730 & 0.729 & 0.745 & 0.747 & 0.739 & 0.724 & 0.735 \\
\hline Zone & Male & 0.462 & 0.456 & 0.459 & 0.463 & 0.464 & 0.455 & 0.460 \\
\cline { 2 - 8 } & Female & 0.464 & 0.459 & 0.459 & 0.473 & 0.474 & 0.461 & 0.465 \\
\hline Difference & Rural & 0.468 & 0.462 & 0.464 & 0.458 & 0.462 & 0.459 & 0.462 \\
\cline { 2 - 8 } & Urbana & 0.459 & 0.454 & 0.455 & 0.471 & 0.471 & 0.457 & 0.462 \\
\hline & Ethnic & 0.371 & 0.375 & 0.375 & 0.375 & 0.375 & 0.374 & 0.374 \\
\cline { 2 - 8 } & Gender & 0.002 & 0.003 & 0.000 & 0.010 & 0.010 & 0.006 & 0.005 \\
\cline { 2 - 8 } & By zone & 0.009 & 0.008 & 0.009 & -0.013 & -0.009 & 0.002 & 0.0005 \\
\hline
\end{tabular}

Source: Prepared by the authors.

As theory suggests, the data show that ethnicity is higher in the case of darker skin tones $(c p>0.45)$, those who self-identify with some ethnic group, immigrants and rural households. Among ethnic groups, Afrodescendants have the highest ethnicity factor, followed by indigenous and roma people, in that order. In contrast, mixed-race people (mestizos), or those who do not self-identify with any ethnic group, have the lowest ethnicity.

\section{The degree of social exclusion (ges) in Colombia}

According to the proposed methodology, Colombia's social exclusion indicator attains an average value of $55 \%$ in terms of household deprivation. The indicator dropped sharply in 2015 , when there was a general improvement in the country's living conditions; but it rose again thereafter (see figure 3).

Figure 3

Colombia: degree of social exclusion, 2012-2017

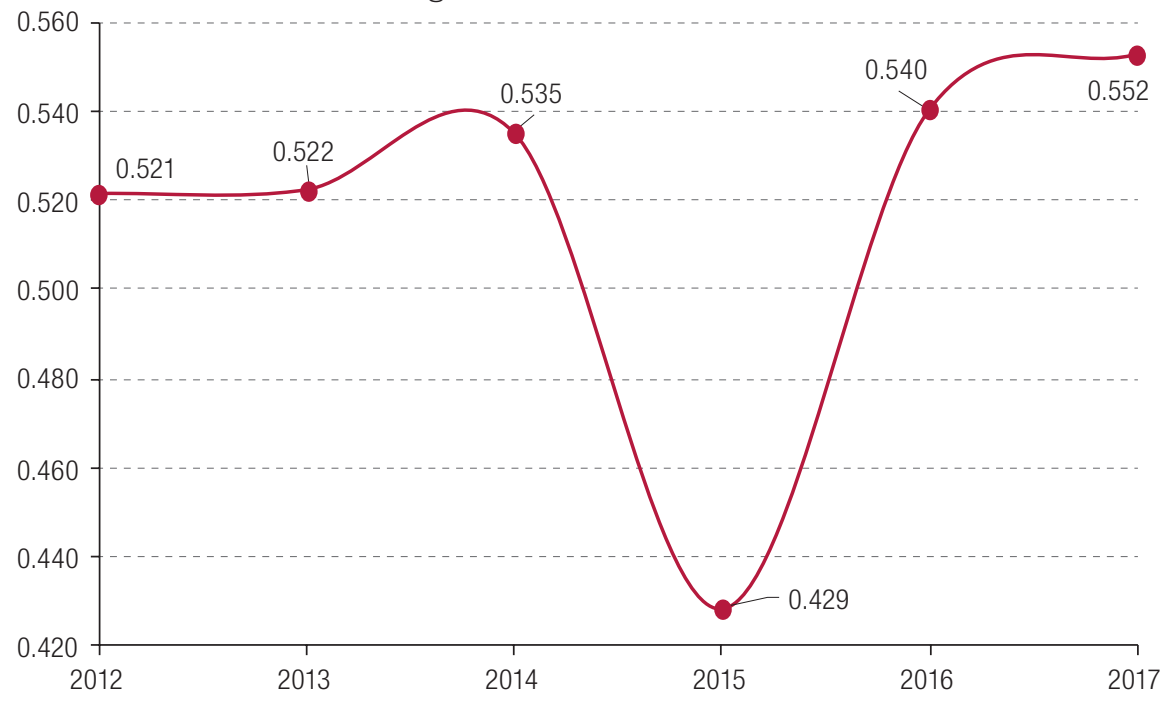

Source: Prepared by the authors. 
Table 3 displays the trend of the indicator during the period of analysis for selected groups of interest. It shows that social exclusion is higher in the population with darker skin $(c p>0.45)$, ethnic groups, men and the rural population.

Table 3

Colombia: social exclusion, by group of interest, 2012-2017

\begin{tabular}{lllllllll}
\hline Variable & Criteria & 2012 & 2013 & 2014 & 2015 & 2016 & 2017 & Total \\
\hline \multirow{2}{*}{ Skin colour (cp) } & $<=0.45$ & 0.519 & 0.521 & 0.533 & 0.428 & 0.539 & 0.549 & 0.512 \\
\cline { 2 - 8 } & $>0.45$ & 0.537 & 0.530 & 0.548 & 0.431 & 0.544 & 0.573 & 0.521 \\
\hline \multirow{2}{*}{$\begin{array}{l}\text { Self-identification with an } \\
\text { ethnic group (age) }\end{array}$} & No & 0.514 & 0.517 & 0.529 & 0.422 & 0.535 & 0.548 & 0.508 \\
\cline { 2 - 8 } & Yes & 0.551 & 0.545 & 0.559 & 0.453 & 0.558 & 0.576 & 0.536 \\
\cline { 2 - 8 } & Roma & 0.476 & 0.480 & 0.464 & 0.497 & 0.462 & 0.545 & 0.479 \\
\cline { 2 - 8 } & Afrodescendants & 0.537 & 0.530 & 0.548 & 0.431 & 0.544 & 0.573 & 0.521 \\
\cline { 2 - 8 } & Indigenous & 0.577 & 0.594 & 0.594 & 0.526 & 0.608 & 0.587 & 0.579 \\
\hline Immigration (im) & No & 0.522 & 0.523 & 0.536 & 0.429 & 0.540 & 0.553 & 0.514 \\
\cline { 2 - 8 } & Yes & 0.419 & 0.467 & 0.475 & 0.371 & 0.510 & 0.535 & 0.466 \\
\hline Gender & Male & 0.526 & 0.527 & 0.540 & 0.431 & 0.544 & 0.549 & 0.516 \\
\cline { 2 - 8 } & Female & 0.513 & 0.514 & 0.527 & 0.424 & 0.534 & 0.557 & 0.508 \\
\hline Zone & Rural & 0.590 & 0.589 & 0.602 & 0.529 & 0.601 & 0.592 & 0.583 \\
\cline { 2 - 8 } & Urbana & 0.478 & 0.481 & 0.491 & 0.368 & 0.503 & 0.532 & 0.471 \\
\hline Difference & Ethnic & 0.037 & 0.028 & 0.030 & 0.031 & 0.023 & 0.028 & 0.028 \\
\cline { 2 - 8 } & Gender & 0.013 & 0.013 & 0.013 & 0.008 & 0.010 & -0.007 & 0.009 \\
\cline { 2 - 8 } & By zone & 0.112 & 0.108 & 0.111 & 0.161 & 0.098 & 0.060 & 0.112 \\
\hline
\end{tabular}

Source: Prepared by the authors.

In general, the social exclusion indicator in Colombia displays a slightly rising trend. There is also a gradual deterioration of living conditions in Colombian households, which is more pronounced in rural areas and in households where ethnicity is greater, either owing to skin colour or through membership of ethnic groups.

\section{The relationship between the ethnicity factor and the degree of social exclusion in Colombia in 2012-2017}

In Colombia, the most intense social exclusion processes definitely occur among the groups or social sectors whose ethnicity factor is higher. This does not mean that there are no other drivers of exclusion in the countries, such as gender, age or religion. What it does seem to mean is that ethnic, racial and nationality differences are among the most prominent factors of social exclusion.

The results of this study reveal a direct and significant relation between the ethnicity factor (fet) and the degree of social exclusion (ges). This relation is obtained from the simple ordinary least squares (OLS) regression shown below:

$$
\operatorname{ges}_{i}=\beta_{0}+\beta_{1} f t_{i}+\mu_{i}
$$

where $\beta_{0}$ represents the coefficient of the intercept, $\beta_{1}$ is the extent to which a variation in ethnicity affects the degree of social exclusion, and $\mu_{i}$ is the error term.

The results of the regression are shown in Figure 4. 
Figure 4

Colombia: relation between the degree of social exclusion and the ethnicity factor, 2012-2017

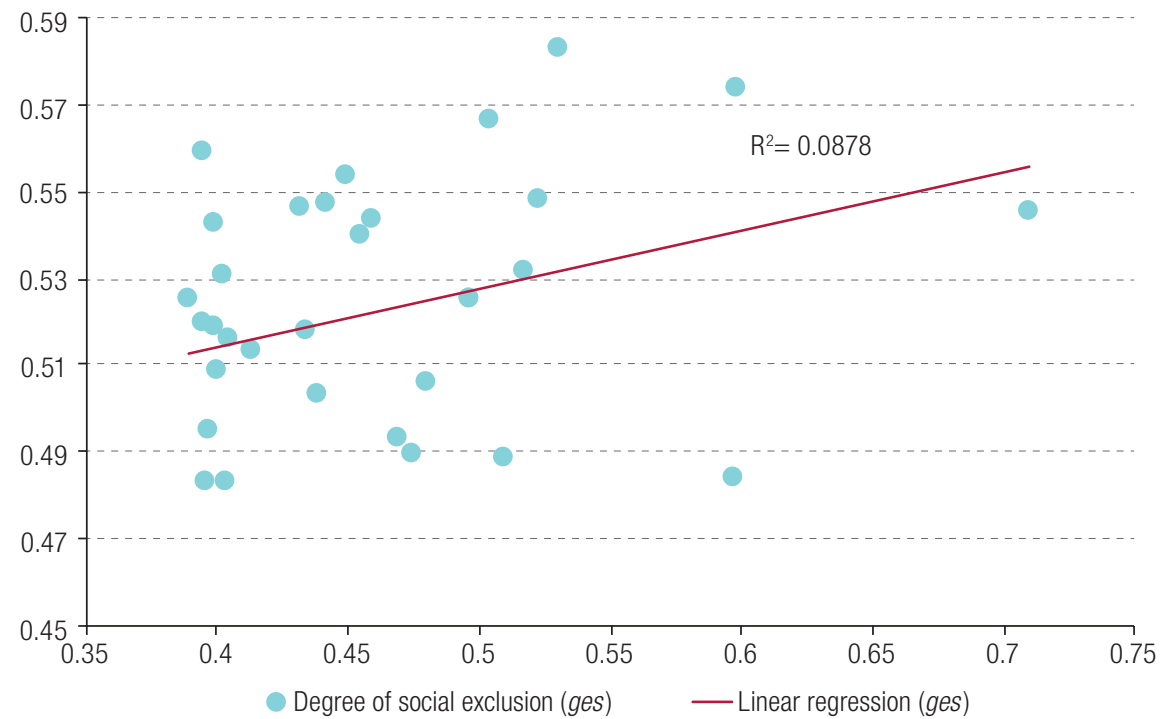

Source: Prepared by the authors.

Note: The relation between the degree of social exclusion (vertical scale) and the ethnicity factor (horizontal scale) was estimated from a simple OLS regression.

This relation is analysed in greater detail through a multiple regression of social exclusion and the ethnicity factor, while controlling for the characteristics of heads of household. This makes it possible to determine whether an increase in ethnicity, either as a whole or in any of its components, increases the degree of social exclusion in the households under study. The information obtained from the ECV is organized into cohorts corresponding to the years 2012-2017, and the following model is established:

$$
Y_{i}=\beta_{0}+\beta_{1} X_{i}+\beta_{2} Z_{i}+\beta_{3} T_{j}+V_{i}
$$

where $Y_{i}$ is the variable that measures social exclusion (ges), $X_{i}$ is the variable that captures ethnicity (fet) or each of its components ( $c p$, age, im), $Z_{i}$ is a vector of control variables, $T_{j}$ is a set of dichotomous variables for each of the years analysed and $V_{i}$ represents the error in the model.

This equation is estimated by OLS to obtain the degree of social exclusion in relation to the ethnicity factor and to each of its component variables. The control variables refer to the personal and sociodemographic data of the heads of household (education, gender, income and area of residence). Dichotomous variables are used to represent the years, since they reflect changes in social exclusion conditional on ethnicity, while holding the passage of time and the other control variables constant.

The results show that the direct relation between ethnicity and social exclusion in Colombia remains significant at a 95\% confidence level: when ethnicity increases by 1 percentage point, social exclusion rises by 7 points (see table 4). 
Table 4

Colombia: linear regression model of the degree of social exclusion, 2012-2017

\begin{tabular}{|c|c|c|c|c|}
\hline \multirow{2}{*}{ Variables } & \multicolumn{4}{|c|}{ Degree of social exclusion } \\
\hline & (1) & (2) & (3) & (4) \\
\hline \multirow[t]{2}{*}{ Ethnicity factor } & $0.0711^{\star \star \star}$ & & & \\
\hline & $(0.00212)$ & & & \\
\hline \multirow[t]{2}{*}{ Education } & $-0.0188^{\star \star \star}$ & $-0.0188^{\star \star \star}$ & $-0.0187^{\star \star \star}$ & $-0.0187^{\star \star *}$ \\
\hline & (7.85e-05) & (7.85e-05) & (7.85e-05) & $(7.89 e-05)$ \\
\hline \multirow[t]{2}{*}{ Per capita income } & $-7.80 \mathrm{e}-09^{\star \star *}$ & $-7.80 \mathrm{e}-09^{\star \star \star}$ & $-7.73 e-09^{\star \star \star}$ & $-8.07 e-09^{* * *}$ \\
\hline & $(2.51 \mathrm{e}-10)$ & $(2.51 \mathrm{e}-10)$ & $(2.51 \mathrm{e}-10)$ & $(2.52 \mathrm{e}-10)$ \\
\hline \multirow[t]{2}{*}{ Male } & 0.000789 & 0.000882 & 0.000829 & 0.000358 \\
\hline & $(0.000673)$ & $(0.000674)$ & $(0.000673)$ & $(0.000676)$ \\
\hline \multirow[t]{2}{*}{ Rural } & $0.0477^{\star * \star}$ & $0.0481^{\star \star \star}$ & $0.0475^{\star \star \star}$ & $0.0479^{\star \star \star}$ \\
\hline & $(0.000712)$ & $(0.000712)$ & $(0.000712)$ & $(0.000715)$ \\
\hline \multirow{2}{*}{2012} & $-0.0569^{\star \star \star}$ & $-0.0567^{\star \star \star}$ & $-0.0572^{\star \star \star}$ & $-0.0564^{\star \star \star}$ \\
\hline & $(0.00124)$ & $(0.00125)$ & $(0.00124)$ & $(0.00125)$ \\
\hline \multirow[t]{2}{*}{2013} & $-0.0525^{\star \star \star}$ & $-0.0526^{\star \star \star}$ & $-0.0527^{\star \star \star}$ & $-0.0523^{\star \star \star}$ \\
\hline & $(0.00124)$ & $(0.00124)$ & $(0.00124)$ & $(0.00125)$ \\
\hline \multirow[t]{2}{*}{2014} & $-0.0416^{\star \star \star}$ & $-0.0417^{\star \star \star}$ & $-0.0418^{\star \star \star}$ & $-0.0413^{\star \star \star}$ \\
\hline & $(0.00126)$ & $(0.00126)$ & $(0.00126)$ & $(0.00126)$ \\
\hline \multirow[t]{2}{*}{2015} & $-0.142^{\star \star \star}$ & $-0.142^{\star \star \star}$ & $-0.142^{\star \star \star}$ & $-0.141^{\star \star *}$ \\
\hline & $(0.00122)$ & $(0.00123)$ & $(0.00122)$ & $(0.00123)$ \\
\hline \multirow[t]{2}{*}{2016} & $-0.0273^{\star \star *}$ & $-0.0273^{* \star *}$ & $-0.0274^{\star \star *}$ & $-0.0264^{* \star *}$ \\
\hline & $(0.00122)$ & $(0.00122)$ & $(0.00122)$ & $(0.00123)$ \\
\hline \multirow[t]{2}{*}{ Skin colour $(c p)$} & & $0.0640^{\star \star \star}$ & & \\
\hline & & $(0.00215)$ & & \\
\hline \multirow{2}{*}{ Self-identification with an ethnic group (age) } & & & $0.0269^{\star * *}$ & \\
\hline & & & $(0.000809)$ & \\
\hline \multirow[t]{2}{*}{ Immigration (im) } & & & & $0.0199^{\star \star \star}$ \\
\hline & & & & $(0.00326)$ \\
\hline \multirow[t]{2}{*}{ Constant (bo) } & $0.676^{\star \star \star}$ & $0.692^{\star \star \star}$ & $0.704^{\star \star \star}$ & $0.709^{\star \star \star}$ \\
\hline & $(0.00162)$ & $(0.00142)$ & $(0.00131)$ & $(0.00131)$ \\
\hline No. of observations & 121419 & 121419 & 121419 & 121419 \\
\hline $\mathrm{R}^{2}$ & $48.5 \%$ & $48.4 \%$ & $48.5 \%$ & $48.0 \%$ \\
\hline
\end{tabular}

Source: Prepared by the authors.

Note: Estimated by ordinary least squares (OLS). Standard errors are indicated in parentheses. ${ }^{\star \star \star} p<0.01,{ }^{\star \star} p<0.05,{ }^{*} p<0.1$.

This regression shows that the direct relationship between social exclusion and ethnicity is maintained when considering each of the components of ethnicity: having a darker skin tone, self-identifying with an ethnic group, or belonging to the immigrant category all increase the degree of social exclusion in Colombia. The model also confirms that having a higher level of education or income counteracts the possibility of being subject to social exclusion, or else makes it easier to escape from that situation. Other control variables, such as residing in rural areas of the country, increase the social exclusion of individuals. Gender, in contrast, does not have a significant impact on the level of social exclusion.

Analysis of the regression in each year of the period under study shows that the results are consistent and that there is a margin of variation of 6-9.4 percentage points for each point of variation in ethnicity. The ethnicity components also display smaller margins each year relative to the overall period; and the coefficient of determination $\left(R^{2}\right)$ remains around $48 \%$ (see table 5). 
Table 5

Colombia: regression of the degree of social exclusion by year, 2012-2017

\begin{tabular}{|c|c|c|c|c|c|c|}
\hline \multirow{2}{*}{ Variables } & \multicolumn{6}{|c|}{ Degree of social exclusion } \\
\hline & 2012 & 2013 & 2014 & 2015 & 2016 & 2017 \\
\hline \multirow[t]{2}{*}{ Ethnicity factor } & $0.0776^{\star \star \star}$ & $0.0685^{\star \star *}$ & $0.0668^{\star \star \star}$ & $0.0942^{\star * \star}$ & $0.0596^{\star \star \star}$ & $0.0595^{\star \star *}$ \\
\hline & $(0.00443)$ & $(0.00443)$ & $(0.00446)$ & (0.00686) & $(0.00387)$ & $(0.00506)$ \\
\hline$R^{2}$ & $48.7 \%$ & $48.0 \%$ & $50.22 \%$ & $45.5 \%$ & $47.2 \%$ & $43.2 \%$ \\
\hline \multirow[t]{2}{*}{ Skin colour } & $0.0769^{\star \star \star}$ & $0.0611^{\star \star *}$ & $0.0641^{\star \star \star}$ & $0.0771^{\star \star \star}$ & $0.0547^{\star \star \star}$ & $0.0533^{\star \star \star}$ \\
\hline & $(0.00459)$ & $(0.00445)$ & $(0.00453)$ & $(0.00697)$ & $(0.00390)$ & $(0.00509)$ \\
\hline$R^{2}$ & $48.6 \%$ & $47.9 \%$ & $50.1 \%$ & $45.4 \%$ & $47.1 \%$ & $43.1 \%$ \\
\hline \multirow[t]{2}{*}{ Ethnic group } & $0.0300^{\star \star \star}$ & $0.0263^{\star \star \star}$ & $0.0255^{\star \star \star}$ & $0.0350^{\star \star \star}$ & $0.0224^{\star \star \star}$ & $0.0213^{\star \star \star}$ \\
\hline & $(0.00167)$ & $(0.00169)$ & $(0.00170)$ & $(0.00262)$ & $(0.00148)$ & $(0.00197)$ \\
\hline$R^{2}$ & $48.7 \%$ & $48.0 \%$ & $50.2 \%$ & $45.5 \%$ & $47.2 \%$ & $43.1 \%$ \\
\hline \multirow[t]{2}{*}{ Immigration } & -0.0107 & $0.0140^{*}$ & $0.0146^{*}$ & $0.0481^{\star \star \star}$ & $0.0161^{\star \star \star}$ & $0.0255^{\star \star \star}$ \\
\hline & $(0.00779)$ & $(0.00717)$ & $(0.00752)$ & (0.0108) & $(0.00603)$ & $(0.00553)$ \\
\hline$R^{2}$ & $47.9 \%$ & $47.4 \%$ & $49.6 \%$ & $45.1 \%$ & $46.6 \%$ & $42.7 \%$ \\
\hline No. of observations & 21171 & 21329 & 20004 & 22829 & 23091 & 12995 \\
\hline
\end{tabular}

Source: Prepared by the authors.

Note: Estimated by ordinary least squares (OLS). Standard errors are indicated in parentheses. ${ }^{* \star *} p<0.01,{ }^{\star \star} p<0.05,{ }^{*} p<0.1$.

Furthermore, by establishing a Mincer equation that includes individual ethnicity, it can be shown that when ethnicity rises, the expected level of income falls, contrary to what happens with years of education (see table 6).

Table 6

Colombia: Mincer equation with respect to ethnicity, 2012-2016

\begin{tabular}{|c|c|c|c|c|}
\hline \multirow{2}{*}{ Variables } & \multicolumn{4}{|c|}{ Natural logarithm of per capita income } \\
\hline & (1) & (2) & (3) & (4) \\
\hline \multirow[t]{2}{*}{ Fet } & $-0.355^{\star \star \star}$ & & & \\
\hline & $(0.0211)$ & & & \\
\hline \multirow[t]{2}{*}{ Education } & $0.122^{\star \star \star}$ & $0.122^{\star \star \star}$ & $0.122^{\star \star \star}$ & $0.122^{\star \star \star}$ \\
\hline & $(0.000910)$ & $(0.000910)$ & $(0.000910)$ & $(0.000912)$ \\
\hline \multirow[t]{2}{*}{ Exper Pot (potential experience) } & $0.0246^{\star \star *}$ & $0.0247^{\star \star \star}$ & $0.0246^{\star \star *}$ & $0.0249^{\star * *}$ \\
\hline & $(0.000672)$ & $(0.000672)$ & $(0.000672)$ & $(0.000673)$ \\
\hline \multirow[t]{2}{*}{ Exper Pot ${ }^{2}$} & $-0.000155^{\star \star \star}$ & $-0.000155^{\star \star \star}$ & $-0.000155^{\star \star \star}$ & $-0.000155^{\star \star \star}$ \\
\hline & $(8.44 \mathrm{e}-06)$ & $(8.44 \mathrm{e}-06)$ & $(8.44 \mathrm{e}-06)$ & $(8.45 e-06)$ \\
\hline \multirow[t]{2}{*}{ Male } & $0.251^{* * *}$ & $0.250^{\star * *}$ & $0.250^{* \star *}$ & $0.253^{\star * *}$ \\
\hline & $(0.00673)$ & $(0.00673)$ & $(0.00672)$ & $(0.00673)$ \\
\hline \multirow[t]{2}{*}{ Urban } & $0.313^{\star \star \star}$ & $0.315^{\star \star \star}$ & $0.312^{\star \star \star}$ & $0.313^{\star \star \star}$ \\
\hline & $(0.00711)$ & $(0.00711)$ & $(0.00710)$ & $(0.00711)$ \\
\hline \multirow[t]{2}{*}{2012} & $-0.398^{\star \star \star}$ & $-0.399^{\star * *}$ & $-0.396^{\star \star \star}$ & $-0.399^{\star \star \star}$ \\
\hline & $(0.0124)$ & $(0.0124)$ & $(0.0124)$ & $(0.0125)$ \\
\hline \multirow[t]{2}{*}{2013} & $-0.330^{\star \star \star}$ & $-0.329^{\star \star \star}$ & $-0.329^{\star \star \star}$ & $-0.329^{\star \star \star}$ \\
\hline & $(0.0124)$ & $(0.0124)$ & $(0.0124)$ & $(0.0124)$ \\
\hline \multirow[t]{2}{*}{2014} & $-0.279^{\star \star \star}$ & $-0.278^{\star \star \star}$ & $-0.277^{\star \star \star}$ & $-0.278^{\star \star \star}$ \\
\hline & $(0.0125)$ & $(0.0125)$ & $(0.0125)$ & $(0.0126)$ \\
\hline \multirow[t]{2}{*}{2015} & $-0.0863^{\star \star \star}$ & $-0.0867^{\star \star \star}$ & $-0.0850^{\star \star \star}$ & $-0.0888^{\star \star \star}$ \\
\hline & $(0.0122)$ & $(0.0122)$ & $(0.0122)$ & $(0.0122)$ \\
\hline \multirow[t]{2}{*}{2016} & $-0.0604^{\star \star \star}$ & $-0.0608^{\star \star \star}$ & $-0.0591^{\star \star \star}$ & $-0.0633^{\star \star \star}$ \\
\hline & $(0.0122)$ & $(0.0122)$ & $(0.0122)$ & $(0.0122)$ \\
\hline
\end{tabular}


Table 6 (concluded)

\begin{tabular}{|c|c|c|c|c|}
\hline \multirow{2}{*}{ Variables } & \multicolumn{4}{|c|}{ Natural logarithm of per capita income } \\
\hline & (1) & (2) & (3) & (4) \\
\hline \multirow[t]{2}{*}{ Skin colour (cp) } & & $-0.286^{\star \star \star}$ & & \\
\hline & & $(0.0214)$ & & \\
\hline \multirow[t]{2}{*}{ Self-identification with an ethnic group (age) } & & & $-0.148^{\star \star \star}$ & \\
\hline & & & $(0.00806)$ & \\
\hline \multirow[t]{2}{*}{ Immigration (im) } & & & & $0.0967^{* \star *}$ \\
\hline & & & & $(0.0326)$ \\
\hline \multirow[t]{2}{*}{ Constant (bo) } & $11.12^{\star \star \star}$ & $11.03^{\star \star \star}$ & $10.99^{\star \star \star}$ & $10.95^{\star \star \star}$ \\
\hline & $(0.0220)$ & $(0.0204)$ & $(0.0195)$ & $(0.0194)$ \\
\hline No. of observations & 120295 & 120295 & 120295 & 120295 \\
\hline$R^{2}$ & $21.4 \%$ & $21.3 \%$ & $21.4 \%$ & $21.2 \%$ \\
\hline
\end{tabular}

Source: Prepared by the authors.

Note: Estimated by ordinary least squares (OLS). Standard errors are indicated in parentheses. ${ }^{\star \star *} p<0.01,{ }^{\star \star} p<0.05,{ }^{*} p<0.1$.

Here again, it can be seen that each of the components of ethnicity is related in the same direction to a person's income: an increase in any of these elements reduces expected income. However, some control variables, such as being male or residing in urban areas of the country, counteract this trend.

\section{Conclusions}

Ethnicity is a socially constructed category that has strong economic implications; it also encompasses other categories that can be used to differentiate between population groups in a given context and time. Race, ethnic origin and immigration are essential components of ethnicity; and they jointly represent the major elements of discrimination and social exclusion inspired by a supposed superiority and legitimacy of some over "others".

Nonetheless, aside from the consensus that may have been reached on this issue, the last three decades have seen increasing recognition of its complexity and importance. Hence interest has arisen in aligning ethnicity to official statistics. However, the definitions of ethnicity and race used in current surveys and census questions depend on the political interpretations, agendas and motivations that lead the governments of each country to undertake this task. Thus, there are multiple biases arising from the operational decisions that are made, with the result that official statistics on ethnic groups are highly unreliable; and, most importantly, it is virtually impossible to make comparisons between countries.

As a strategy to overcome this problem, census questionnaires or household surveys need to be redefined in order to separate the elements that make up ethnicity and then recombine in a comprehensive measure, which is here called the ethnicity factor (fet).

Social exclusion, meanwhile, is a concept and a phenomenon that the social sciences are still constructing and reconstructing, owing to the dispersion of meanings and discourses that denote different realities for the same process. Nonetheless, social exclusion could be defined as a set of structural [and institutional] mechanisms that [systematically] prevent certain social groups from participating fully in the economic, social, political and cultural spheres of society (Valdivia, Benavides and Torero, 2007, p. 604).

As social exclusion is a multidimensional, multicausal, structural and dynamic phenomenon that is also defined by the accumulation of deficits (deprivations) that are interrelated and feed back on each other, the concept encompasses many of the elements that Alkire and Foster (2007) use to calculate multidimensional poverty. This study therefore proposes the degree of social exclusion (ges) as an alternative measure and as a variation on the multidimensional poverty index (MPI) used by DANE in Colombia, based on household deprivations in 15 variables and five dimensions, according to a normative threshold (zj) established for each variable. 
The data show that Colombia is a highly ethnic country, since the ethnicity factor is approximately 0.46 on a scale of 0 to 1 in the period analysed. The data also reveal that, as theory suggests, ethnicity is greater in the case of darker skin tones ( $c p>0.45)$, those who self-identify with an ethnic group, and among immigrants and rural households. Moreover, the country's social exclusion indicator attains an average value of $55 \%$ in terms of household deprivation. The indicator dropped sharply in 2015 , when there was a general improvement in the country's living conditions, but rose again in subsequent years. It also disproportionately affects rural areas and households where ethnicity is higher, either owing to skin colour or through belonging to ethnic groups.

In Colombia, the most intense social exclusion processes are clearly experienced in the groups or social sectors that have higher ethnicity factors. This does not mean that there are no other drivers of exclusion in the countries, such as gender, age or religion. What it does seem to mean is that ethnic, racial and nationality differences are among the most prominent factors of social exclusion. The results reveal a direct and significant relation between the ethnicity factor (fet) and the degree of social exclusion (ges) in the country: when the former increases by 1 percentage point, the latter rises by 7 points at a 95\% confidence level. Similarly, having a darker skin tone, self-identifying with an ethnic group, being an immigrant and living in rural areas all increase the degree of exclusion. In contrast, having a higher level of education or higher per capita income counteracts this effect. Lastly, the gender of the head of household does not significantly affect the level of social exclusion.

\section{Bibliography}

Alkire, S. and J. Foster (2007), "Counting and multidimensional poverty measurement", OPHI Working Papers, No. 7, Oxford Poverty and Human Development Initiative (OPHI).

Antón, J. and F. Del Popolo (2009), "Visibilidad estadística de la población afrodescendiente de América Latina: aspectos conceptuales y metodológicos", Afrodescendientes en América Latina y el Caribe: del reconocimiento estadístico a la realización de derechos, Population and Development series, No. 87 (LC/L.3045-P), J. Antón and others, Santiago, Economic Commission for Latin America and the Caribbean (ECLAC).

Bello, Á. and M. Rangel (2000), Etnicidad, "raza" y equidad en América Latina y el Caribe (LC/R.1967/Rev.1), Santiago, Economic Commission for Latin America and the Caribbean (ECLAC).

Blanco, C. (2000), Las migraciones contemporáneas, Madrid, Alianza Editorial.

Bodnar, Y. (2005), "Pueblos indígenas de Colombia: apuntes sobre la diversidad cultural y la información sociodemográfica disponible", Notas de Población, No. 79 (LC/G 2284-P), Santiago, Economic Commission for Latin America and the Caribbean (ECLAC).

CONAPO (National Population Council) (2009), "Migración Internacional”, Informe de Ejecución: Programa de Acción de la Conferencia Internacional sobre la Población y el Desarrollo 1994-2009, Mexico City.

Dagum, C., R. Gambassi and A. Lemmi (1992), "New approaches to the measurement of poverty", Poverty Measurement for Economies in Transition in Eastern European Countries, Warsaw, Polish Statistical Association/Central Statistical Office.

DANE (National Administrative Department of Statistics) (2009), La visibilización estadística de los grupos étnicos colombianos, Bogotá.

(2007), Colombia una nación multicultural: su diversidad étnica [online] https://www.dane.gov.co/files/ censo2005/etnia/sys/colombia_nacion.pdf.

Domínguez, J. and J. Núñez (2013), "Exclusión social nos fogares españois: un estudo comparativo rexional durante o período 2004-2008", Revista Galega de Economía, vol. 22, extraordinary issue, September.

ECLAC (Economic Commission for Latin America and the Caribbean) (2008), Preliminary Overview of the Economies of Latin America and the Caribbean, 2008 (LC/G.2401-P), Santiago.

Estivill, J. (comp.) (2004), Pobreza y exclusión en Europa: nuevos instrumentos de investigación, Barcelona, Hacer.

Fernández de Labastida, I. (n/d), "Tema 6: etnicidad e inmigración”, University of the Basque Country [online] https://ocw.ehu.eus/pluginfile.php/53497/mod_resource/content/1/Tema_6._Etnicidad_e_inmigracion.pdf. 
Gacitúa, E. and S. Davis (2001), "Introduction: poverty and social exclusion in Latin America and the Caribbean", Social Exclusion and Poverty Reduction in Latin American and the Caribbean, E. Gacitúa, C. Sojo and S. Davis (eds.), Washington, D.C., World Bank.

Godínez-Montoya, L., E. Figueroa-Hernández and F. Pérez-Soto (2014), "Nueva reconfiguración de la inmigración internacional: el caso de España”, Hitos demográficos del siglo XXI: migración internacional, J. González Becerril, B. Montoya Arce and A. Barreto Villanueva (coords.), Toluca, Autonomous University of the State of Mexico.

Goldberg, C. (2007), "Reflexiones en torno a la medición de la etnicidad en censos y encuestas", paper presented at the ninth Argentine Conference on Population Studies, Huerta Grande, Argentine Association of Population Studies (AEPA), 31 October-2 November.

Good Gingrich, L. and N. Lightman (2015), "The empirical measurement of a theoretical concept: tracing social exclusion among racial minority and migrant groups in Canada", Social Inclusion, vol. 3, No. 4, July.

Guimarães, A. (1999), "Raça e os estudos de relações raciais no Brasil”, Novos Estudos, No. 54, São Paulo, Brazilian Centre of Analysis and Planning (CEBRAP).

Hernández Pedreño, M. (coord.) (2008), "Pobreza y exclusión en las sociedades del conocimiento”, Exclusión social y desigualdad, M. Hernández Pedreño (coord.) Murcia, University of Murcia Publishing Services.

Hernández Romero, A. (2008), "La experiencia de la identificación étnica en los Censos de Población de Colombia: Ios retos para el próximo censo", paper presented at the seminar-workshop "Censos 2010 y la inclusión del enfoque étnico: hacia una construcción participativa con pueblos indígenas y afrodescendientes de América Latina", Santiago, 19-21 November.

Hopenhayn, M. and Á. Bello (2000), "Tendencias generales, prioridades y obstáculos en la lucha contra el racismo, la discriminación racial, la xenofobia y las formas conexas de intolerancia. América Latina y el Caribe", paper presented at the Latin American and Caribbean Regional Seminar of Experts on Economic, Social and Legal Measures to Combat Racism with Particular Reference to Vulnerable Groups, Santiago, 25-27 October.

IGOP (Institute of Government and Public Policy) (2003), Un paso más hacia la inclusión social: generación de conocimiento, políticas y prácticas para la inclusión social, Madrid, NGO's Platform for Social Action.

Jiménez Ramírez, M. (2008), "Aproximación teórica de la exclusión social: complejidad e imprecisión del término. Consecuencias para el ámbito educativo", Estudios Pedagógicos, vol. XXXIV, No. 1, Valdivia, Austral University of Chile.

Lenoir, R. (1974), Les exclus: un Française sur dix, Paris, Éditions du Seuil.

Loktieva, I. (2016), "Approaches to empirical analysis of social exclusion: international comparison", Economics and Sociology, vol. 9, No. 2.

Morning, A. (2008), "Ethnic classification in global perspective: a cross-national survey of the 2000 census round", Population Research and Policy Review, vol. 27, February.

Oommen, T. (1994), "Race, ethnicity and class: an analysis of interrelations", International Social Science Journal, No. 139, February.

Peligero Escudero, P. (2006), "Inmigración y mercado laboral”, El control de los flujos migratorios hacia España: situación actual y propuestas de actuación, Documentos de Seguridad y Defensa, No. 6, Higher National Defense Studies Center.

Piqueras, A. (2002), "La identidad", Introducción a la antropología para la intervención social, I. de la Cruz (coord.) and others, Valencia, Tirant lo Blanch.

Rangel, M. (2004), "Género, etnicidad, pobreza y mercado de trabajo en Bolivia, Ecuador, Guatemala y Perú", Desigualdades entrecruzadas: pobreza, género, etnia y raza en América Latina, M. E. Valenzuela and M. Rangel (eds.), Santiago, International Labour Organization (ILO).

Raya Díez, E. (2006), Indicadores de exclusión social: una aproximación al estudio aplicado de la exclusión, Bilbao, University of the Basque Country.

Schkolnik, S. (2009), "La inclusión del enfoque étnico en los censos de población de América Latina", Notas de Población, No. 89 (LC/G.2427-P), Santiago, Economic Commission for Latin America and the Caribbean (ECLAC).

Schkolnik, S. and F. Del Popolo (2006), "Los censos y los pueblos indígenas en América Latina: una metodología regional”, Pueblos indígenas y afrodescendientes de América Latina y el Caribe: información sociodemográfica para políticas y programas, Project Documents (LC/W.72), Santiago, Economic Commission for Latin America and the Caribbean (ECLAC). 
Stavenhagen, R. (2002), "La diversidad cultural en el desarrollo de las Américas: los pueblos indígenas y los Estados nacionales en Hispanoamérica", Organization of American States (OAS) [online] http://www.oas. org/udse/espanol/cpo_cult_public.asp.

Tedesco, L. (2010), “Latinoamericanos en España: de la integración al retorno”, Inmigración latinoamericana en España: el estado de la investigación, A. Ayuso and G. Pinyol (eds.), Barcelona, CIDOB Foundation.

Telles, E. (2014), Pigmentocracies: Ethnicity, Race, and Color in Latin America, Chapel Hill, The University of North Carolina Press.

Telles, E. and L. Steele (2012), "Pigmentocracy in the Americas: how is educational attainment related to skin color?", Americas Barometer Insights: 2012, No. 73, Latin American Public Opinion Project (LAPOP).

Trouillot, M.-R. (2001), "Social exclusion in the Caribbean", Social Exclusion and Poverty Reduction in Latin American and the Caribbean, E. Gacitúa, C. Sojo and S. Davis (eds.), Washington, D.C., World Bank.

Valdivia, N. (2011), El uso de categorías étnico/raciales en censos y encuestas en el Perú: balance y aportes para una discusión, Documento de Investigación, No. 60, Lima, Group for the Analysis of Development (GRADE).

Valdivia, N., M. Benavides and M. Torero (2007), "Exclusión, identidad étnica y políticas de inclusión social en el Perú: el caso de la población indígena y la población afrodescendiente", Investigación, políticas y desarrollo en el Perú, Lima, Group for the Analysis of Development (GRADE).

Wade, P. (2011), "Raza y naturaleza humana", Tabula Rasa, No. 14, January-June.

World Bank (2013), Inclusion Matters: The Foundation for Shared Prosperity, Washington, D.C. 